\title{
Directed motivational currents: An agenda for future research
}

\author{
Christine Muir a * (D), Özge Gümüş b \\ a University of Nottingham, University Park, Nottingham, NG7 2RD, UK \\ ${ }^{b}$ Adlyaman University, Altınşehir Neighbourhood, Adlyaman, 02040, Turkey
}

\begin{tabular}{l|l|l} 
Received 24 August 2020 & Received in revised form 4 November 2020 & Accepted 5 November 2020
\end{tabular}

\begin{abstract}
APA Citation:
Muir, C. \& Gümüş, Ö. Directed motivational currents: An agenda for future research. Eurasian Journal of Applied Linguistics, 6(3), 501-519.
\end{abstract}

Doi: $10.32601 /$ ejal.834661

\begin{abstract}
Directed motivational currents (DMCs) encapsulate a unique motivational phenomenon. DMCs are highly positive, potent motivational experiences which can carry individuals or groups forwards to achieving valued goals at both a remarkable rate, and with a perceived feeling of seemingly 'effortless effort'. Although research into DMCs began under a decade ago (Dörnyei, Ibrahim \& Muir, 2015; Dörnyei, Muir \& Ibrahim, 2014; Henry, Davydenko \& Dörnyei, 2015; Muir \& Dörnyei, 2013), the motivational experience DMCs encapsulate is, in and of itself, certainly not novel. DMCs appear to be widely recognizable in diverse contexts, and may even be relatively widely experienced (Muir, 2020). The theoretical underpinning of DMC theory draws together findings from a broad range of well-established motivational disciplines in related areas of psychology (including cognitive and educational psychology), alongside motivation research rooted more fully in the context of language learning (LLing) and teaching. We begin by overviewing the DMC construct itself, outlining key cornerstones and primary theoretical principles that underpin our understanding of each. We go on to lay out a broad agenda for further study, continuing the discussion in the final chapter of Muir (2020), by foregrounding six avenues for future research. Viewed together, they are demonstrative of the scope of future research potential surrounding DMC theory, incorporating both theoretical and applied (pedagogic) directions for inquiry. For each future avenue that we propose, we foreground several more specific directions in which research effort might begin.
\end{abstract}

(C) 2020 EJAL \& the Authors. Published by Eurasian Journal of Applied Linguistics (EJAL). This is an open-access article distributed under the terms and conditions of the Creative Commons Attribution license (CC BY-NC-ND) (http://creativecommons.org/licenses/by-nc-nd/4.0/).

Keywords: directed motivational currents/DMCs; language learner motivation; long-term motivation; project based learning

\section{Introduction}

Directed motivational currents (DMCs) encapsulate a unique motivational phenomenon. DMCs are highly positive, potent motivational experiences which can carry individuals or groups forwards to achieving valued goals at both a remarkable rate, and with a perceived feeling of seemingly 'effortless effort'. Although research

\footnotetext{
* Corresponding author. Tel.: +44-115-74-84727

E-mail address: christine.muir@nottingham.ac.uk http://dx.doi.org/.10.32601/ejal.834661
} 
began under a decade ago (Dörnyei, Ibrahim \& Muir, 2015; Dörnyei, Muir \& Ibrahim, 2014; Henry, Davydenko \& Dörnyei, 2015; Muir \& Dörnyei, 2013), the motivational experience DMCs encapsulate is, in and of itself, certainly not novel. DMCs appear to be widely recognizable in diverse contexts, and may even be relatively widely experienced (Muir, 2020). The theoretical underpinning of DMC theory (see Dörnyei, Henry \& Muir, 2016) draws together findings from a broad range of well-established motivational disciplines in related areas of psychology (including cognitive and educational psychology), alongside motivation research rooted more fully in the context of language learning (LLing) and teaching.

We begin by offering an introduction to directed motivational currents, outlining key cornerstones and primary theoretical principles that underpin our understanding of each. We go on to lay out a broad agenda for further study, continuing the discussion in the final chapter of Muir (2020). We foreground six avenues for future research. Viewed together, they are demonstrative of the scope of future research potential surrounding DMC theory, incorporating both theoretical and applied (pedagogic) directions for inquiry. For each future avenue that we propose, we foreground several more specific directions in which research effort might begin.

\section{What is a directed motivational current?}

Directed motivational currents (DMCs) can be experienced both individually and in groups. As a springboard for discussion, we begin by offering an example of each. In an ESL context, an individual-DMC might be experienced by a student hoping to move to Australia to undertake his MA degree. His academic grades are more than adequate, yet his offer remains contingent on the results of his IELTS exam: in the months prior, the DMC he experiences sees him entirely wrapped up in his studies, and he finds himself able to concentrate for longer, and more deeply, than he had previously been able to. Up until the day he takes the test, his every free moment is taken up with thinking about English and the vision of all that it will mean to him to be successful (for well documented individual-DMCs in varied LLing contexts, see Henry et al., 2015; Safdari \& Maftoon, 2017; Selçuk \& Erten, 2017; Zarrinabadi \& Tavakoli, 2017). An example of a group-DMC might be witnessed among students volunteering to put on a summer fete for the private language school at which they are studying. All immigrants to the UK, this project empowers the group to not only engage more deeply and more positively with their local community, but also to share their cultures, heritage and passions with all those around them. In the run up to the event, the students find themselves working productively together, actively seeking out new language as and when they need it, putting themselves in communicative scenarios they had previously lacked confidence to engage in, and fully dedicated to putting on the best event possible for their peers, teachers, and local community (for examples of group-DMCs, see Dörnyei et al., 2016; Muir, 2020; Muir, Florent \& Leach, 2020; Sampson, 2016). 
A primary cornerstone of all DMC experiences is a clear goal or vision directing action. This functions to align the diverse tasks and activities that an individual or group must undertake en route to goal achievement. In understanding the motivating capacity of DMCs, goal-setting theory (Locke \& Latham, 2006) is extended by drawing from findings in the areas of vision, self-concordant goals and proximal subgoals (Henry et al., 2015). The notion of self-concordant goals (goals that are both deepseated and highly identity-relevant, Sheldon \& Elliot, 1999) is particularly important; it is unlikely that any goal is capable of supporting a DMC. Initial conceptualisations of DMCs likened their motivational trajectory to that of a rocket, following a relatively predictable path "as determined by the conditions surrounding its launch" (Dörnyei et al., 2015: 103). That a situation's initial conditions are critical to its subsequent functioning is a core tenet of a complex dynamic systems (CDS) approach to understanding (Hiver \& Papi, 2019). The immeasurable number of factors contributing to any situation's initial conditions means that accurate prediction of DMC emergence is impossible. However, steps can be taken to make specific motivational emergence more likely (Davis \& Sumara, 2006), implying tangible pedagogical applications. Research to date has taken initial steps in investigating the emergence of DMCs (e.g., in relation to specific goals and triggers, Ibrahim, 2017; Muir, 2020; Selçuk \& Erten, 2017; Zarrinabadi et al., 2019; See Future avenue 1) and there has similarly been initial investigation of the application of DMC theory to language pedagogy via group projects (e.g., Dörnyei et al., 2016; Muir, 2020; Muir et al., 2020; See Future avenues 1, 3 and 4).

A second cornerstone of DMC theory relates to their structure. All DMCs have a clearly identifiable starting point, and the current of motivation emerged is continually re-triggered up until the point the experience ends, thus supporting a sustained stream of motivation. While experiencing a DMC, an individual's ideal L2 self (Dörnyei, 2009) becomes a part of who they are in the present: it is not only more frequently activated, it tends to be more widely activated, even in situations where the final goal may not appear to be immediately foregrounded (Dörnyei et al., 2016; see Lenton et al., 2013). In practical terms, there are several key elements of a DMC's structure. The first of these is the emergence of regular behavioural routines. These can be seen, for example, in the descriptions of Bina, Athena and Oksana, who each experienced a DMC learning Swedish, and who carved out specific periods of time each day dedicated to study (Henry et al., 2015). A further important structural element is the existence of proximal subgoals (Bandura \& Schunk, 1981; a chain of short-term goals comprising a longer-term goal pathway). In the context of DMCs, these serve not only as targets to aim for and markers by which personal progress can be judged, but they also play a key role with regards to the accessibility of affirmative feedback (positive progress feedback), which is integral to processes supporting continued goal striving (see e.g. Henry et al., 2015; Sak, 2019; Zarrinabadi \& Tavakoli, 2017). Individuals experiencing DMCs appear to be highly attuned and receptive to feedback opportunities, interpreting as such even non-verbal cues from those around them (Dörnyei et al., 2016; see Future avenues 1 \& 4). 
A third cornerstone of DMC theory is their highly positive emotionality, conspicuous across all DMC experiences. This is associated with all tasks in a DMC pathway, even those that, when completed in contexts other than that of a DMC, may not be perceived as inherently enjoyable (such as giving up multiple evenings a week in order to travel an hour each way to attend language classes, as was the case for Tina during her DMC learning Italian; Safdari \& Maftoon, 2017). This experiential element of a DMC has close parallels with Csikszentmihalyi's notion of flow (1975/2000), and indeed, individuals may even experience discrete instances of flow within a longer DMC pathway. Flow and DMCs are conceptually distinct. They differ, for example, in the source of the positive emotionality characteristic of both (in flow, this is associated with the joy intrinsic to completing the task itself, whereas in DMCs, it is rooted in the utility of the task in contributing to longer-term goal achievement), and the timescales over which they extend (flow experiences typically last a maximum of hours, DMCs more typically extend over weeks or months; for more detailed discussion see Dörnyei et al., 2016, Chapter 1). The positive emotionality of DMCs stems from experiences of eudaimonia (deep-seated feelings of satisfaction and contentment with where one is, and what one is doing; Waterman, 1993): it is in this respect that the relevance of self-concordant goals become selfevident.

In recent years, motivation literatures, both mainstream and in the context of LLing, have turned to recognise motivation as a dynamic construct (Hiver \& Papi, 2019). Such a perspective foregrounds motivation as ever in flux, evolving and developing over time and in response to interrelated context- and situational-factors (each themselves also dynamic), and across multiple different timescales. As Henry (2019: 144) describes, "The DMC construct is a product of this shift in the theorizing of motivation." The DMC structure intertwines, over time, both a final goal/vision energising action with an action plan capable of guiding an individual to realise these aims: this 'perfect match' functions to amplify rather than absorb energy (Dörnyei et al., 2016). It is owing to this self-sustaining nature of DMCs - integrating both cause and effect, meaning that "the outworking of the initial motive becomes part of the energy source itself” (Dörnyei et al., 2016: xii) - that DMCs occupy a unique position in the landscape of motivation research. While DMCs are ongoing, they are able to regulate fluctuation in individuals' experiences of long-term goal striving (Gümüş, 2019; Selçuk \& Erten, 2017), and align diverse factors against the backdrop of our chaotic world. DMCs have thus been argued to open up a "window for systematic research into motivational dynamics” (Dörnyei et al., 2015: 98).

\section{DMCs: An agenda for future research}

The study of DMCs remains in its infancy, yet it is supported by a growing body of empirical research. This has included confirmatory studies, interrogating the underpinnings of DMC theory (e.g. Henry et al., 2015; Safdari \& Maftoon, 2017; Zarrinabadi \& Tavakoli, 2017), qualitative research investigating specific aspects of the DMC experience (e.g. positive emotionality, Ibrahim, 2016; and characteristics of 
DMC emergence, Ibrahim, 2017; Muir, 2020), and research investigating the relationships between DMCs and related areas of interest (such as autonomy and selfefficacy, e.g. Pietluch, 2018, 2019; Zarrinabadi et al., 2019). Quantitative investigation has begun to assess the relevance and generalisability of the DMC framework more broadly (e.g. Muir, 2020; Ghanizadeh \& Jahedizadeh, 2017), and there have also been inroads interrogating implications for language pedagogy, both conceptually (e.g. with Dörnyei et al.'s, 2016, seven proposed frameworks for focused interventions) and empirically (e.g. Muir, 2020; Muir et al., 2020; Sampson, 2016).

In proposing each of the six avenues below, we offer further commentary regarding specific research gaps and scope for development. We highlight research completed to date, related findings from other areas of investigation, and offer rationale for the value of further study in this area. For each future avenue put forward, we suggest several more specific directions in which work might begin.

\subsection{Future avenue 1. Triggering and re-triggering the current: The launch and continuation of DMCs}

Dörnyei et al. (2016: 59) propose that "the successful launch of a DMC relies on two key factors: the alignment of the necessary conditions and the availability of a specific triggering stimulus": the effectiveness of any triggering stimulus in facilitating DMC emergence is therefore dependent on its relationship with the various contextual, personal, and time factors it intersects with. Key elements of these initial conditions are thought to include a clear set of goals, a sense of individual ownership and control, perceived balance of challenges and skills - i.e., confidence that one's skills match up to task demands - and openness to the DMC experience (we return to this, that is, an individuals' propensity to experience DMCs, in Future avenue 2). In the context of group DMCs, this final condition is superseded by a group-level equivalent; "the maturity of the group to work independently" (Dörnyei et al., 2016: 151). For Ibrahim's (2017) participants, the two most important conditions emerged were the existence of clear goals (it is noteworthy that these tended to begin as rooted in participants' wider career goals and other life ambitions, becoming more concrete and language-specific when paired with a suitable trigger; see also Selçuk \& Erten, 2017), perceived feasibility of success, and levels of control. Gümüş's (2019) work has further indicated the importance of a situation's initial conditions or parameters as moderating a trigger's effectiveness, and Sak (2019) similarly underlines the link between DMCs and earlier learning experiences.

Examples of DMC triggers include an attractive opportunity or reactance to a negative experience (see Dörnyei et al., 2016; Ibrahim, 2017; Zarrinabadi et al., 2019). In the most comprehensive study investigating DMC triggers to date, Muir (2020) categorized the triggers reported by her 1,452 participants into four distinct groupings: triggers linked to positive external influences (e.g. a final piece of the puzzle falling into place), triggers linked to negative external influences (e.g. a form of reactance/need to save face), outcome-led triggers (e.g. a single, explicit goal/vision), 
and triggers linked to more interpersonal reasons (e.g. finding a new passion and immediately becoming hooked). Ibrahim (2017) highlighted five triggers igniting his participants' DMC experiences (a negative emotion, meeting others who shared similar passions, emergent opportunities, new information, and moments of realization/awakening), and the qualitative accounts he presents offer insight into the interrelationships between these triggers and the context in which they acted.

The value of exploring these questions (and, conversely, barriers to DMC emergence and continuance; Muir, 2021) lies in the potential to obtain a more effective toolkit able to purposefully facilitate and support LLing DMCs in pedagogic settings (see Future avenues $3 \& 4$ ).

Research avenue 1a: Reflecting the importance of a situation's initial conditions to subsequent functioning, dedicated investigation of the dynamic relationship between specific DMC triggers and the environment in which they are situated is needed, to develop further the generally more descriptive work already conducted in this area. Building on retrospective studies providing detailed description of participants' LLing DMC experiences (e.g. Ibrahim, 2017; Safdari \& Maftoon, 2017; Zarrinabadi \& Tavakoli, 2017), methods such as Retrodictive Qualitative Modelling (RQM; Dörnyei, 2014) have the potential to shed light on this interaction; differences/commonalities, for example, in the environments of individuals whose DMC was sparked by the same type of trigger.

Research avenue 1b: Research to date has focused on triggers as linked to DMC emergence, yet a DMC is supported over time by a continued re-triggering of the current after distractions (Dörnyei et al., 2016). Little is known about the characteristics or the specific functioning of these 're-triggers'. For example, it is not clear what forms or types these 're-triggers' might take; whether the types of triggers identified in datasets relating to the point of DMC emergence may map similarly onto novel datasets of 're-triggers'. Focus may be directed towards commonalities in these 're-triggers' in DMCs with similar/different end goals, and specific emotions these instances of re-triggering elicit and how this contributes to, or otherwise influences, the overall positive emotionality of the DMC experience (see Ibrahim, 2016). This question is of equal importance where 're-triggers' are and where they are not successful in maintaining the DMC current (investigating the motivational dynamics of unsuccessful DMCs may have much to contribute to the way in which teachers manage specific aspects of classroom practice and materials design in relation to DMC emergence).

\subsection{Future avenue 2. DMCs and individual differences}

Research in the context of flow theory and personality psychology on the correlates of a propensity to experience flow has confirmed the presence of an autotelic personality, thus representing an individual difference factor in flow experiences (Johnson, Keiser, Skarin, \& Ross, 2014; Ross \& Keiser, 2014). It has been hypothesised that a similar personality trait may also be identifiable in relation to 
DMCs (Dörnyei et al., 2016). Subsequent research (e.g. Gümüş, 2019, Muir, 2020; Selçuk \& Erten 2017; Ghanizadeh \& Jahedizadeh, 2017) has indicated that some people have indeed experienced DMCs on more than one occasion, and that some may have a particular set of personality traits or competences which make them more prone to experiencing DMCs. Research on the notion of autotelic personality has, however, remained a relatively minor focus of flow research (Swann, Keegan, Piggott \& Crust, 2012), and it may be that future research in each context can productively contribute to the other. This avenue of research is imperative from the perspective of pedagogic application, with respect to the appropriacy of enacting dedicated interventions rooted in DMC theory in specific contexts.

A plausible point at which to begin to explore a personality trait factor in the context of DMCs is to explore similar factors that have been identified in relation to autotelic personalities in the flow literature. Much of this research has been in relation to the 'big five' or 'five factor' model (FFM) of personality - comprising openness, conscientiousness, neuroticism, agreeableness, and extraversion - with Costa and McCrae's (1992) inventory most commonly employed in many empirical studies (e.g. Johnson et al., 2014; Ross \& Keiser, 2014). Supported by other work in this area (e.g. Johnson et al., 2014; Ullén et al., 2012), Ross and Keiser concluded that "findings suggest a substantial degree of overlap between flow-propensity in general life and FFM personality traits, indicating that autotelic personality can be 'captured' to a large extent in an FFM nomological network" (2013: 6). Traits that have emerged most prominently in their ability to predict an individual's propensity to experience flow include higher conscientiousness and lower neuroticism (higher emotional stability; Johnson et al., 2014; Ross \& Keiser, 2014; Ullén et al., 2016; Ullén et al., 2012). Research has focused not only on these 'big five', but also the facets of which each is comprised (for example, the positive correlation of higher conscientiousness with a propensity to experience flow has been demonstrated to be most strongly related to the facets of self-discipline and achievement-striving; Ross \& Keiser, 2014), and Ross and Keiser (2014) have further investigated the relationship between the FFM and discrete aspects of the flow experience.

Other lines of research investigating various temperament dimensions have found persistence and novelty seeking to be strong predictors of flow (e.g. Teng, 2011), and Keller and Bless (2008) and Keller and Blomann (2008) have found a systematic relationship between individual differences in various self-regulatory competencies and flow experiences. Relevant personality traits are further discussed by Baumann (2012) as representational of differences in an individual's need for achievement and key competencies related to self-regulation, both of which she positions as "boundary conditions of flow" (p. 168). Future research investigating these factors and individuals' propensity to experience DMCs may prove fruitful.

A related research direction has been investigation of the relationships between an individual's DMC Disposition (a composite variable comprised of 10 Likert statements tapping into all elements of the DMC construct; Muir, 2020) and other psychological variables. To date, this has included investigation of the relationship with an 
individual's willingness to communicate (WTC), autonomy, self-confidence and selfconcept (Zarrinabadi et al., 2019), and self-efficacy (Pietluch 2018, 2019). In future, research might also explore other relationships, for example with past attributions, mindsets, and creativity, to name but a few. The development of such an agenda would also provide a valuable starting point for research relating to potential ongoing effects from DMC experiences (see Future avenue 5). Although this future avenue is premised on the supposition that there is a subset of people who are likely to be more highly disposed to experience DMCs than others, Dörnyei et al. (2016) have argued that, with suitable environment and opportunity, it might be the case that all individuals may be able to experience this type of motivational emergence.

Future avenue 2a: Of the FFM (Costa \& McCrae, 1992), high conscientiousness and low neuroticism have most strongly correlated with an individual's propensity to experience flow: this suggests a practical starting point from which a similar line of research may be followed in relation to DMCs. Large-scale quantitative questionnaire studies investigating any such correlations might draw on scales and study designs already validated in previous work in these areas.

Future avenue 2b: Drawing on, for example, Başöz and Erten $(2018,2019)$, a further fruitful future avenue will be to continue the investigation of links between individuals' experiences of DMCs and their WTC: between differences and/or any changes in students' WTC during projects that do and do not facilitate group-DMC emergence (see Future avenue 3); relationships between individuals' [individual/group, in-class/out-of-class] DMC experiences and their [in-class/out-ofclass] WTC; the period of time over which any [positive/negative] changes in WTC linked to DMC experiences may endure (see also Future avenue 5). Due to the ability of DMCs to support individuals acting in manners over and above what they may typically be capable of, classroom observations may be a productive means by which to collect data regarding students in-class WTC prior to and during an intensive group project/group-DMC experience (see Future avenue 3). Furthermore, extracts of recordings taken as part of this data collection may even be used to support students' continued language development, for example via the use of video selfmodelling/'success tapes' (Vlaeva, under review).

\subsection{Future avenue 3. Pedagogical implications 1: Group-DMCs and projects}

The way educational projects are implemented in pedagogic settings can vary widely. Although educational projects are not a novel methodological approach, empirical work rooted in project-based learning has historically lacked a robust theoretical foundation (Stoller, 2006). A "more complex instructional concept than the term suggests" (Stoller, 2006: 21), theoretical underpinning for projects has tended to look instead to literatures related to purported positive outcomes, for example learner motivation, autonomy and self-confidence (Stoller, 2006; Muir, 2019). DMC theory has been positioned as able to further develop the theoretical foundation for projects by offering a coherent and comprehensive framework and springboard for development 
which, particularly in the context of LLing, "the field has heretofore been lacking" (Muir, 2020: 202).

There is a considerable body of research around project-based learning in general education, and a burgeoning foundation is emerging rooted in the context of LLing (Beckett \& Chamness-Miller, 2006; Beckett \& Slater, 2020; Gras-Velázquez, 2020). A related area of study relevant to our understanding of project design is task-based language teaching (TBLT). Although there is a sizeable literature on TBLT, focus has tended to centre on cognitive rather than motivational aspects of task design (see Dörnyei, 2019). Research investigating, for example, the effects of task design on various aspects of a learner's engagement, both with the task itself and with their peers (e.g. Erten \& Altay, 2009), will doubtless be highly pertinent (owing to the recognition that, fundamentally, projects are comprised of a series of interlinked tasks).

In their 2016 book, Dörnyei et al. proposed seven 'frameworks for focused interventions' as a starting point for the practical application of DMC theory to language pedagogy. These seven project design variants each position a different cornerstone of DMC theory as the primary motivational driver. For example, the positive emotionality of the DMC experience is core to the 'That's me!' project framework, whereas DMC structure is central to the 'Step by Step' and 'Story Sequels' variants. This conceptualisation similarly acknowledges that different project designs will be suitable for different classroom contexts, different student groupings, and as directed towards different pedagogic aims. Muir (2020) prefers to talk of projects 'with $D M C$ potential', emphasising the fact that any project design may only be considered as having the potential to facilitate this type of motivational emergence, that it cannot ever be considered guaranteed.

Initial empirical support for the 'DMC potential' of one of these project frameworks ('All Eyes on the Final Product', centered around a clear, overarching end goal) to be able to facilitate a group-DMC has been demonstrated with a class of EFL Business English learners studying at a private language school in Australia (Muir, 2020; Muir et al., 2020). There emerged convincing evidence that this project design, which challenged students to organise and host a charity fundraising event, did facilitate the emergence of a powerful group-DMC, yet research to date has only taken first steps in exploring the practical application of DMC theory.

Research avenue 3a: Initial empirical evidence has suggested that an 'All Eyes on the Final Product' project template does indeed have some 'DMC potential'. Immediate follow on areas of inquiry therefore include interrogation of the efficacy of this project design in different contexts, with different learner groups, taught by different teachers, and directed towards different end goals. Muir (2020) and Muir et al. (2020) offer a practical template that such a research direction might take, with collected data including interviews, observations, and participant journals (see Muir, 2021, for discussion of practical approaches to researching group-DMCs specifically from a CDS perspective). 
Research avenue 3b: A criticism of L2 motivation research more broadly has been that many empirical studies rely on outcome variables such as intended effort, instead of seeking to relate findings to specific aspects of L2 development (Ushioda, 2016). Research centered around group-DMCs, due to the inherently goal-orientedness and largely self-contained teaching sequences of projects, may be ideally placed to address this call. Muir (2020) reported considerable language development as perceived by participants in relation to (productive) vocabulary skills and speaking/listening fluency, among other areas. Focus on tracing these aspects of language development (that were facilitated by an 'All eyes on the final product' project design) would provide a productive starting point for future replication studies. Ushioda (2016) also highlights several practical inroads, with the accessible and adaptable 'research tasks' she suggests all tailored to the 'small lens' investigation of students' motivation and language development. Other fruitful areas of study in this vein include the investigation of variation (in relation to the amount/aspects of) in language development in students compared with (a) each other, and (b) students completing a similar project design but from which a group-DMC does not emerge.

\subsection{Future avenue 4. Pedagogical implications: Instructed classroom environments and individual-DMCs}

Managing a group's dynamic and the development of positive student roles, norms, and whole group cohesiveness is a fundamental component of a teacher's role (Dörnyei \& Muir, 2019). Individual-DMCs, however, are rooted in highly identity-relevant, supremely personal goals, and, with this in mind, it is not immediately apparent the ways in which general classroom practice might seek to support students experiencing them.

Sak's (2019) study, investigating the effect of contextual factors on DMC processes in instructed settings, reports on two participants experiencing individual-DMCs and highlights several valuable points of departure. Both were triggered by course enrolment and the opportunity to devote more time to study, however, both students' DMC goals - for Duygu, to be able to speak freely in English while travelling and in her personal and professional life, and for Özge, a long awaited opportunity to 'prove' herself and her English competence - are ultimately unrelated to it. Sak's analysis highlights key ways in which the course was able to support their DMC experiences, and areas in which it struggled to do so. One area that both Duygu and Özge commented on was the importance of the instructed classroom environment in relation to receiving affirmative feedback (a core part of a DMC's structure supporting ongoing momentum). This positive progress feedback appeared to take on additional significance for both participants throughout their DMC, and this was particularly true for Özge, whose anxiety levels rose as she sought even to avoid taking exams for fear of receiving negative feedback. It is similarly interesting to note that both participants rated their classes most highly when "the teacher taught well" (Özge; p. 168). As Sak (2019: 168) reflects, those classes which were rated most highly were characterised by, "teaching procedures which provide room for individual autonomy 
and self-expression": that is, we might speculate, those teaching procedures that best allowed Duygu and Özge to enact their autonomy to adapt and use these lessons to serve their own ends (i.e., to act as stepping stones in their individual-DMC pathways). Gümüş's (2019) study, exploring the in-class motivational and affective states, and effort fluctuation patterns of EFL learners, and specific factors influencing these ebbs and flows, offers similar conclusions. The teacher and their teaching practice was found to play a critical role in supporting a student, Lexa, in experiencing an individual-DMC, with specific factors emerged including the availability of supplementary materials, the teacher's ability to facilitate an enjoyable and sharing atmosphere, the teacher's perceived emotional state, and all students' active engagement in the lesson.

A wide range of micro-level factors in instructed language classroom contexts are likely to enhance and impair students' DMC experiences. This is similarly true for both individual-DMCs, as in these examples here, and when group-DMCs emerge across classes as a whole (as discussed in Future avenue 3). Fruitful areas of inquiry may therefore center around the ways in which DMC experiences are both promoted and inhibited as dependent on context-related and situation-specific parameters related to instructed language classrooms, and the resultant effects on students' experiences.

Research avenue 4a: To develop an empirical basis for the development of broad principles that teachers might incorporate into their pedagogy in order to support students experiencing individual, LLing-focused DMCs at the time of attending their classes, further research into the ways in which individual-DMC experiences are promoted and/or inhibited by context and situation-specific parameters within language classrooms is needed. Focusing on feedback may be a fruitful starting point. For example, this might see investigation exploring whether, and in what ways, students' experiencing individual-DMCs engage differently with in-class feedback compared to their peers not experiencing individual-DMCs; whether there is variation of engagement linked to different types of feedback/different means by which it is given; what lessons might be extrapolated from students' increased engagement with feedback throughout DMCs that could be used to support other students' receptivity to the same feedback opportunities. Retrospective interviews conducted immediately after (group-)DMCs end, analysed alongside rich datasets collected as they unfold would allow for a better understanding of learners' lived experiences, allowing researchers also to better identify and interpret any 'rose tinted glasses' participants may later don.

\subsection{Future avenue 5. DMCs and longer-term positive effects}

From a pedagogical perspective, perhaps one of the most compelling questions for study is whether there may be positive longer-term effects to experiencing DMCs. There has yet to be any dedicated empirical study in this area, yet in the context of LLing, Muir (2020) has foregrounded the relevance of findings recently emerged in 
the study abroad literature, particularly the context of short-term study abroad (STSA; typically lasting between three to eight weeks, Badstübner \& Ecke, 2009). It is widely acknowledged, equally in anecdotal and empirical accounts, that periods of study abroad do not lead reliably to uniform experiences of student success, even for students in seemingly identical environments (Churchill \& DuFon, 2006; Kinginger, 2011). Some students do, however, make remarkable progress, and evidence is emerging that suggests some of these positive effects may endure (for example, in relation to students' ideal L2 selves, effort and self-efficacy; Fryer \& Roger, 2018; Ueki \& Takeuchi, 2016). Drawing on Fryer and Roger's (2018) discussion of DMCs and their participants' experiences during and subsequent to periods of STSA, Muir (2020) has argued that the positive after-effects documented may not be solely rooted in the STSA experience itself, but that instead the critical factor may have been the experience of a DMC.

Seeking to facilitate DMC experiences for students through the introduction of projects 'with DMC potential' (see Future avenue 3) is undoubtedly time, resource and effort intensive. Yet, additional justification for such investments would be found if discrete positive outcomes from the experience may be demonstrated to endure after a DMC comes to an end.

Research avenue 5a: The starting point for research must be to empirically document any long-term effects of LLing DMCs (assessed e.g. at 2/6/9 months after a DMC ends), as experienced in a broad array of teaching and learning contexts, and in relation to both individual and group-DMCs. This question could fruitfully be investigated both in the context of STSA and in other teaching and learning contexts, alongside investigation of variability in the extent and type of long-term effect documented both between individuals, and as linked to different project frameworks and end goals. Enduring positive outcomes documented in the STSA literature relate to students' motivation, ideal L2 selves, effort and self-efficacy (Fryer \& Roger, 2018; Ueki \& Takeuchi, 2016), indicating a practical potential starting point for research.

Research avenue 5b: It may not be the case that ongoing positive effects are witnessed after every DMC experience. In such cases, in-depth, qualitative case studies (Duff, 2020) may shed light on why some individuals do not go on to experience anticipated or hoped-for effects. Investigation might include the identification and exploration of specific barriers, and seek potential mitigations able to help lessen the impact (that might then be incorporated into teaching sequences in instructed contexts).

\subsection{Future avenue 6. DMCs and long-term motivation}

DMCs are unique among other experiences of successful, long-term goal striving individuals experiencing DMCs do not need to rely on perseverance, grit, or other highly self-regulated forms of behaviour in order to sustain the current of motivation - DMCs have thus been positioned as representing a 'perfect' form of approach motivation (Dörnyei et al., 2016). The distinction between approach and avoidance 
motivation has long been recognised in psychology, yet across the field of LLing, research into regulatory focus has received only marginal attention (Csizér, 2019; Papi et al., 2019).

Addressing this call and arguing similarly, Henry and Davydenko (2020) extend the analysis of Henry et al. (2015; which investigated the DMCs of three adult learners of Swedish) by exploring the experiences of another subset of participants who were similarly motivated to achieve long-term L2 goals, but who did not experience DMCs. Drawing on the approach-avoidance dichotomy, in their analysis Henry and Davydenko highlight several key participant profiles. One comprised participants whose "approach disposition of becoming proficient in Swedish was matched by an approach-oriented regulation pattern" (Henry \& Davydenko, 2020: 369): that is, their motivation was like valenced (see Elliot, Eder \& Harmon-Jones, 2013). Examples of these participants' goals included the development or continuation of their professional identities in the new country they called home. Another participant profile included participants who exhibited a similar approach disposition, but instead paired this with avoidance-focused regulation (it was opposite balanced). Examples of these participants' goals included wanting to avoid the need to apply for financial support via state benefits, or to avoid being negatively positioned as an immigrant who could not speak the language. Long-term motivation has been positioned as a key area for future research (Dörnyei, 2020), and Henry and Davydenko's (2020) use of DMC theory as a template for study suggests its utility beyond that rooted solely in understanding the DMC experience in and of itself.

Another area of emerging interest in the context of LLing is language learner engagement (Mercer \& Dörnyei, 2020; Hiver, Al-Hoorie \& Mercer, 2020). Although definitional distinctions between the terms 'motivation' and 'engagement' continue to be a subject of discussion, the "core notion" at the center of this is that of action (Mercer, 2019: 3): a highly motivated language learner may not go on to exhibit actual engagement in productive learning behaviours. Research into language learner engagement is a relatively young field of investigation in context of LLing, yet it is already well-established in mainstream education, where it has been described as "the holy grail of learning" (Sinatra et al., 2015: 1).

Mercer (2019: 6) has argued that DMC theory may provide a key avenue for the further development of understanding related to language learner engagement. As she describes:

What is needed is a holistic framework that brings together various strands to understand language learning engagement as an action component of dynamic motivational processes in multilevel ecologies, such as within schools, classrooms, and interactions, and on micro- and macro-timescales such as across years of schooling and within the minutes of working on a task.

Mercer positions DMCs as having already begun to forge this path. She further argues that continued development here, and of understanding relating to motivational antecedents and conditions, conversely including also factors which may 
act as barriers to language learner engagement (see also Muir, 2021), will be central to achieving this more holistic understanding. Rather than focusing on self-regulatory strategies aimed at limiting the loss of motivational momentum once it has begun, DMC theory centers its focus instead on the "positive contributions of goal striving" (Dörnyei et al., 2016: 27):

DMCs concern the motivational components and conditions that can energize engagement with an ongoing project, and reflect exactly the kind of holistic comingtogether of all the necessary parts which theoretical accounts in mainstream psychology have been lacking. (Dörnyei et al., 2016: 35)

The motivational current emerged in a DMC is thus capable of facilitating "an optimal form of engagement with an extended project" (Dörnyei et al., 2016: 33), and in so doing, it "can be seen to offer an optimal template for understanding long-term motivated behavior" (Dörnyei et al., 2016: 35).

Research avenue 6a: Selçuk \& Erten's (2017) and Gümüş’s (2019) findings indicate that individuals experiencing DMCs may demonstrate more stable longitudinal trajectories than motivated individuals not experiencing DMCs. DMCs are able to cut through the complexity of the surrounding environment, and function to align diverse factors towards a single outcome (Dörnyei et al., 2015). It may thus be reasonable to conclude that the experience of DMCs might also positively affect other elements related to the longitudinal stability of motivated action. Building on initial work in this area, future research might productively investigate the longitudinal stability of variables such as ideal L2 selves, effort, self-efficacy and WTC, both over time, and compared to that of highly motivated individuals who are not experiencing DMCs.

Research avenue $6 b$ : Student engagement is a multifaceted construct, comprising cognitive, affective and behavioural aspects (Fredricks et al., 2004). With a view to better supporting teachers' ability to construct project designs that are able to support specific aspects of students' engagement, Ushioda's (2016) small lens approach may again offer productive, practical inroads. Issues of interest may include the extent to which specific aspects of students' engagement varies with different project designs, or between similar project designs directed towards different end goals, and the extent to which students' engagement (and various aspects of) is variable among individual group members throughout and/or subsequent to a group-DMC (and factors that might explain this variation).

\section{Conclusions}

In this paper, we have laid out six future avenues for DMC research, drawing on and developing Muir's (2020) recent discussion. Although not comprehensive, these six avenues demonstrate the scope and potential for further study in this area. To complement each future avenue, we have pinpointed several more specific areas for investigation, and have been able to comment briefly on practical methodological approaches that might be adopted. The broad scope of research directions covered emphasises the importance of methodological diversity and innovation in future work. 
LLing motivation research has experienced a revolution in recent years with the broad adoption of a CDS approach to understanding (Hiver \& Papi, 2019), and the field of applied linguistics more widely, too, has taken advantage of this moment in time to take stock, and to more consciously consider and develop the theoretical principles underpinning field-specific methods (McKinley, 2020). Simultaneously embracing the CDS approaches gaining acceptance, and the methodological innovation emerged partly as a direct result thereof (Hiver \& Al-Hoorie, 2020), suggests high promise for future research efforts and findings awaiting ahead. We feel confident that the potential rewards of these labours with respect to the future of DMC research will be worth the effort.

\section{Acknowledgements}

Prof. Dr. Erten was a generous and supportive of graduate students and early career researchers. We would like to express our sincere and deepest gratitude to Prof. Dr. İsmail Hakkı Erten for his valuable contributions to the field. Me, Özge, as having been his $\mathrm{PhD}$ student, I hope I can put forward research that will really do his memory justice.

\section{The Conflict of Interest Statement}

In line with the statement of Committee on Publication Ethics (COPE), we hereby declare that we had no conflicting interests regarding any parties of this study.

\section{References}

Badstübner, T., \& Ecke, P. (2009). Student expectations, motivations, target language use, and perceived learning progress in a summer study abroad program in Germany. Die Unterrichtspraxis/Teaching German, 42(1), 41-49. https://doi.org/10.1111/j.17561221.2009.00034.x

Bandura, A., \& Schunk, D. H. (1981). Cultivating competence, self-efficacy, and intrinsic interest through proximal self-motivation. Journal of Personality and Social Psychology, 41(3), 586-598. https://doi.org/10.1037/0022-3514.41.3.586

Başöz, T., \& Erten, İ. H. (2018). Investigating tertiary level EFL learners' willingness to communicate in English. English Language Teaching, 11(3), 78-87. http://doi.org/10.5539/elt.v11n3p78

Başöz, T., \& Erten, İ. H. (2019). A qualitative inquiry into the factors influencing EFL learners' in-class willingness to communicate in English. Novitas-ROYAL (Research on Youth and Language), 13(1), 1-18.

Baumann, N. (2012). Autotelic personality. In S. Engeser (Ed.), Advances in flow research (165-186). New York: Springer.

Beckett, G. H., \& Chamness Miller, P. (Eds.) (2006). Project-based Second and Foreign Language Education: Past, Present and Future. Greenwich, CT: Information Age Publishing.

Beckett, G. H. \& Slater, T. (Eds.) (2020). Global Perspectives on Project-based Language Learning, Teaching, and Assessment: Key Approaches, Technology Tools, and Frameworks. Abingdon, Oxford: Routledge. 
Costa, P. T., \& McCrae, R. R. (1992). NEO personality inventory professional manual. Odessa, FL: Psychological Assessment Resources.

Churchill, E. \& DuFon, M. A. (2006). Evolving threads in study abroad research. In M. A. DuFon \& E. Churchill (Eds.), Language learners in study abroad contexts (1-27). Clevedon, UK: Multilingual Matters.

Csikszentmihalyi, M. (1975/2000). Beyond boredom and anxiety. San Francisco: Jossey-Bass.

Csizér, K. (2019). The L2 motivational self system. In M. Lamb, K. Csizér, A. Henry \& S. Ryan (Eds.), The Palgrave handbook of motivation for language learning (71-93). London: Palgrave MacMillan.

Davis, B., \& Sumara, D. (2006). Complexity and Education: Enquiries into Learning, Teaching and Research. Mahwah, NJ: Lawrence Erlbaum.

Dörnyei, Z. (2009). The L2 motivational self system. In Z. Dörnyei \& E. Ushioda (Eds.), Motivation, Language Identity and the L2 Self (9-42). Bristol: Multilingual Matters.

Dörnyei, Z. (2014). Researching complex dynamic systems: 'Retrodictive qualitative modelling' in the language classroom. Language Teaching, 47(1), 80-91. https://doi.org/10.1017/S0261444811000516

Dörnyei, Z. (2019). Task motivation: What makes an L2 task engaging? In Z. Wen \& M. J. Ahmadian (Eds.), Researching L2 task performance and pedagogy: In honour of Peter Skehan (53-66). Amsterdam: John Benjamins.

Dörnyei, Z. (2020). Innovations and challenges in language learning motivation. London: Routledge.

Dörnyei, Z., Henry, A., \& Muir, C. (2016). Motivational currents in language learning: Frameworks for focused interventions. New York: Routledge.

Dörnyei, Z., Ibrahim, Z., \& Muir, C. (2015). 'Directed Motivational Currents': Regulating complex dynamic systems through motivational surges. In Z. Dörnyei, P. D. MacIntyre \& A. Henry (Eds.), Motivational Dynamics in Language Learning (95-105). Bristol: Multilingual Matters.

Dörnyei, Z., \& Muir, C. (2019). Creating a motivating classroom environment. In X. A. Gao (Ed.), Second Handbook of English Language Teaching (719-736). New York: Springer.

Dörnyei, Z., Muir, C., \& Ibrahim, Z. (2014). Directed motivational currents: Energising language learning through creating intense motivational pathways. In D. Lasagabaster, A. Doiz \& J. M. Sierra (Eds.), Motivation and Foreign Language Learning: From Theory to Practice (9-29). Amsterdam: John Benjamins.

Duff, P. (2020). Case study research: Making language learning complexities visible. In J. McKinley \& H. Rose (Eds.), The Routledge Handbook of Research Methods in Applied Linguistics (144-153). Oxford: Routledge.

Elliot, A. J., Eder, A. B., \& Harmon-Jones, E. (2013). Approach-avoidance motivation and emotion: Convergence and divergence. Emotion Review, 5, 308-311. https://doi.org/10.1177/1754073913477517

Erten, İ. H., \& Altay, M. (2009). The effects of task-based group activities on students' collaborative behaviours in EFL speaking classes. Journal of Theory and Practice in Education, 5(1), 33-52.

Fredricks, J. A., Blumenfeld, P. C., \& Paris, A. H. (2004). School engagement: potential of the concept, state of the evidence. Review of Educational Research, 74(1), 59-109. https://doi.org/10.3102/00346543074001059

Fryer, M., \& Roger, P. (2018). Transformations in the L2 self: Changing motivation in a study abroad context. System, 78, 159-172. https://doi.org/10.1016/j.system.2018.08.005 
Ghanizadeh, A., \& Jahedizadeh, S. (2017). Directed motivational currents: The implementation of the dynamic web-based Persian scale among Iranian EFL learners. Journal of Language Teaching Skills, 36(1), 27-56. https://doi.org/10.22099/jtls.2017.23952.2159

Gümüş, Ö. (2019). Exploring directed motivational currents of English as a foreign language learners at the tertiary level through the dynamic systems perspective. Unpublished doctoral dissertation. University of Hacettepe, Turkey.

Gras-Velazquez, A. (Ed.) (2020). Project-Based Learning in Second Language Acquisition: Building Communities of Practice in Higher Education. London: Routledge.

Henry, A. (2019). Directed motivational currents. In M. Lamb, K. Csizér, A. Henry \& S. Ryan (Eds.), The Palgrave Handbook of Motivation for Language Learning (139-162). Basingstoke: Palgrave.

Henry, A., \& Davydenko, S. (2020). Thriving? Or Surviving? An approach-avoidance perspective on adult language learners' motivation. The Modern Language Journal, 104(2), 363-380. https://doi.org/10.1111/modl.12635

Henry, A., Davydenko, S., \& Dörnyei, Z. (2015). The anatomy of directed motivational currents: Exploring intense and enduring periods of L2 motivation. Modern Language Journal, 99(2), 329-345. https://doi.org/10.1111/modl.12214

Hiver, P., \& Al-Hoorie, A. (2020). Research methods for complexity theory in applied Linguistics. Bristol: Multilingual Matters.

Hiver, P., Al-Hoorie, A., \& Mercer, S. (2020). Student Engagement in the Language Classroom. Bristol: Multilingual Matters

Hiver, P., \& Papi, M. (2019). Complexity theory and L2 motivation. In M. Lamb, K. Csizér, A. Henry \& S. Ryan (Eds.), The Palgrave Handbook of Motivation for Language Learning (117-138). Basingstoke: Palgrave.

Ibrahim, Z. (2016). Affect in directed motivational currents: Positive emotionality in long-term L2 engagement. In P. MacIntyre, T. Gregersen \& S. Mercer (Eds.), Positive Psychology in Second Language Acquisition (258-281). Bristol: Multilingual Matters.

Ibrahim, Z. (2017). Parameters inducing motivational surges in second language learning. UKH Journal of Social Sciences, $1(1), \quad 24-33$. http://doi.org/10.25079/ukhjss.v1n1y2017.pp24-33

Johnson, J. A., Keiser, H. N., Skarin, E. M. \& Ross, S. R. (2014). The Dispositional flow scale-2 as a measure of autotelic personality: An examination of criterion related validity. Journal of Personality Assessment, 96, 465-470. https://doi.org/10.1080/00223891.2014.891524

Keller, J., \& Bless, H. (2008). Flow and regulatory compatibility: An experimental approach to the flow model of intrinsic motivation. Personality and Social Psychology Bulletin, 34, 196209. https://doi.org/10.1177/0146167207310026

Keller, J., \& Blomann, F. (2008). Locus of control and the flow experience: An experimental analysis. European Journal of Personality, 22, 589-607. https://doi.org/10.1002/per.692

Kinginger, C. (2011). Enhancing language learning in study abroad. Annual Review of Applied Linguistics, 31, 58-73. https://doi.org/10.1017/S0267190511000031

Lenton, A. P., Bruder, M., Slabu, L., \& Sedikides, C. (2013). How does 'being real' feel? The experience of state authenticity. Journal of Personality, 8(3), 276-289. https://doi.org/10.1111/j.1467-6494.2012.00805.x

Locke, E. A. \& Latham, G. P. (2006). New directions in goal-setting theory. Current Directions in Psychological Science, 15(5), 265-268. https://doi.org/10.1111/j.14678721.2006.00449.x 
McKinley, J. (2020). Introduction: Theorizing research methods in the 'golden age' of applied linguistics research. In J. McKinley \& H. Rose (Eds.), The Routledge Handbook of Research Methods in Applied Linguistics (1-12). Abingdon, Oxford: Routledge.

Mercer, S. (2019). Language learner engagement: Setting the scene. In A. Gao (Ed.), Second Handbook of English Language Teaching. New York: Springer.

Mercer, S., \& Dörnyei, Z. (2020). Engaging Language Learners in Contemporary Classrooms. Cambridge: Cambridge University Press.

Muir, C. (2019). Motivation and Projects. In M. Lamb, K. Csizér, A. Henry \& S. Ryan (Eds.), The Palgrave Handbook of Motivation for Language Learning (327-346). Basingstoke: Palgrave.

Muir, C. (2020). Directed motivational currents and language education: Exploring implications for pedagogy. Bristol: Multilingual Matters.

Muir, C. (2021). Investigating group-DMCs and complexity in the L2 classroom. In R. Sampson \& R. Pinner (Eds.), Complexity Perspectives on Researching Language Learner and Teacher Psychology (189-207). Bristol: Multilingual Matters.

Muir, C., \& Dörnyei, Z. (2013). Directed motivational currents: Using vision to create effective motivational pathways. Studies in Second Language Learning and Teaching, 3(3), 357-375. https://doi.org/10.14746/ssllt.2013.3.3.3

Muir, C., Florent, J., \& Leach, D. (2020). Managing motivational group projects. Journal of Languages, Texts and Society, 4.

Papi, M., Bondarenko, A. V., Mansouri, S., Feng, L., \& Jiang, C. (2019). Rethinking L2 motivation research: The $2 \times 2$ model of L2 self-guides. Studies in Second Language Acquisition, 41, 337-361. https://doi.org/10.1017/S0272263118000153

Pietluch, A. (2018). Extraordinary motivation or a high sense of personal agency: The role of self-efficacy in the Directed Motivational Currents theory. New Horizons in English Studies, 3, 45-56. https://doi.org/10.17951/nh.2018.45

Pietluch, A. (2019). Stimulating educational growth through vision and self-efficacy: a case study of adult users of English as a foreign language. Crossroads: A Journal of English Studies, 27, 58-76. https://doi.org/10.15290/cr.2019.27.4.04

Ross, S. R., \& Keiser, H. N. (2014). Autotelic personality through a five-factor lens: Individual differences in flow-propensity. Personality and Individual Differences, 59, 3-8. https://doi.org/10.1016/j.paid.2013.09.029

Safdari, S., \& Maftoon, P. (2017). The rise and fall of directed motivational currents: A case study. Journal of Language Teaching and Learning, 7(1), 43-54.

Sak, M. (2019). Contextual factors that enhance and impair directed motivational currents in instructed 12 classroom settings. Novitas-ROYAL (Research on Youth and Language), 13(2), $155-174$

Sampson, R. (2016). Complexity in Classroom Foreign Language Learning Motivation. A Practitioner Perspective from Japan. Bristol: Multilingual Matters.

Selçuk, Ö. \& Erten, İ. H. (2017). A display of patterns of change in learners' motivation: Dynamics perspective. Novitas-ROYAL (Research on Youth and Language), 11(2), 128-141.

Sheldon, K. M., \& Elliot, A. J. (1999). Goal striving, need satisfaction, and longitudinal wellbeing: The self-concordance model. Journal of Personality and Social Psychology, 76(3), 482-497. https://doi.org/10.1037/0022-3514.76.3.482

Sinatra, G. M., Heddy, B. C., \& Lombardi, D. (2015). The challenges of defining and measuring student engagement in science. Educational Psychologist, 50(1), 1-13. https://doi.org/10.1080/00461520.2014.1002924 
Stoller, F. (2006). Establishing a theoretical foundation for project-based learning in second and foreign language contexts. In G. H. Beckett \& P. Chamness Miller (Eds.), Project-based Second and Foreign Language Education (19-40). Greenwich, CT: Information Age Publishing.

Swann, C., Keegan, R. J., Piggott, D., \& Crust, L. (2012). A systematic review of the experience, occurrence, and controllability of flow states in elite sport. Psychology of Sport and Exercise, 13(6), 807-819. https://doi.org/10.1016/j.psychsport.2012.05.006

Teng, C.-I. (2011). Who are likely to experience flow? Impact of temperament and character on flow. Personality and Individual Differences, 50(6), 863-868. https://doi.org/10.1016/j.paid.2011.01.012

Ueki, M. \& Takeuchi, O. (2016). The impact of studying abroad experience on the affective changes related to L2 motivation: A qualitative study of the processes of change. In M. Apple, D. Da Silva \& T. Fellner (Eds.), L2 Selves and Motivations in Asian Contexts (119133). Bristol: Multilingual Matters.

Ullén, F., Harmat, L., Theorell, T., \& Madison, G. (2016). Flow and individual differences-a phenotypic analysis of data from more than 10,000 twin individuals. In L. Harmat, F. Ørsted Andersen, F. Ullén, J. Wright \& G. Sadlo (Eds.), Flow experience (267-288). Cham, Switzerland: Springer International Publishing.

Ullén, F., de Manzano, Ö., Almeida, R., Magnusson, P. K., Pedersen, N. L., Nakamura, J., Csíkszentmihályi, M., \& Madison, G. (2012). Proneness for psychological flow in everyday life: Associations with personality and intelligence. Personality and Individual Differences, 52, 167-172. https://doi.org/10.1016/j.paid.2011.10.003

Ushioda, E. (2016). Language learning motivation through a small lens: A research agenda. Language Teaching, 49(4), 564-577. https://doi.org/10.1017/S0261444816000173

Vlaeva, D. (under review). Enhancing L2 motivation through video self-modelling: Insights from an exploratory study. Language Learning \& Technology.

Waterman, A. S. (1993). Two conceptions of happiness: Contrasts of personal expressiveness (eudaimonia) and hedonic enjoyment. Journal of Personality and Social Psychology, 64(4), 678-691. https://doi.org/10.1037/0022-3514.64.4.678

Zarrinabadi, N., Ketabi, S., \& Tavakoli, M. (2019). Directed Motivational Currents in L2: Exploring the Effects on Self and Communication. Cham: Springer.

Zarrinabadi, N., \& Tavakoli, M. (2017). Exploring motivational surges among Iranian EFL teacher trainees: Directed motivational currents in focus. TESOL Quarterly, 51(1), 155166. https://doi.org/10.1002/tesq.332

\section{Copyrights}

Copyright for this article is retained by the author(s), with first publication rights granted to the Journal.

This is an open-access article distributed under the terms and conditions of the Creative Commons Attribution license (CC BY-NC-ND) (http://creativecommons.org/licenses/by-nc-nd/4.0/). 